\title{
RISK ASSESSMENT OF AFLATOXIN IN BRAZIL NUT BY PRODUCT CONSUMPTION IN THE AMAZON REGION
}

\section{ARIANE KLUCZKOVSKI ${ }^{1 *}$, CIBELE VIANA ${ }^{1}$, JANAÍNA BARRONCAS ${ }^{1}$, EMERSON LIMA ${ }^{1}$, CAROLINA VALENTIM ${ }^{1}$, LAWRENCE XAVIER ${ }^{1}$, PEDRO CAMPELO ${ }^{2}$, AUGUSTO KLUCZKOVSKI ${ }^{3}$}

${ }^{1}$ Faculty of Pharmaceutical Sciences, Federal University of Amazonas, Amazonas, Brazil. ${ }^{2}$ Faculty of Agrarian Sciences, Federal University of Amazonas, Amazonas, Brazil. ${ }^{3}$ Federal University of Santa Catarina, Santa Catarina, Brazil. Email: ariane@ufam.edu.br

Received: 30 March 2020, Revised and Accepted: 20 May 2020

ABSTRACT

Objective: Evaluate exposure to aflatoxins in processed Brazil nut (chopped and sliced) products marketed in Amazonas State.

Methods: The samples were purchased during the 2017 harvest at the local retail in the city of Manaus/AM/Brazil in the form of sliced and chopped. Moisture content (MC) and water activity (aw) were verified, aflatoxins (AFB1, AFB2, AFG1, AFG2) were quantified by liquid chromatography. To characterize the risk of exposure to genotoxic use the population margin of exposure (MOE).

Results: Chopped and sliced Brazil nut samples analyzed here presented an MC average of $1.62 \%$ and water activity of 0.26 . These values indicate that samples are safe, according to physical-chemical baselines. Regarding aflatoxins presence, $8 \%$ of the samples presented aflatoxins total levels $>10 \mu \mathrm{g} / \mathrm{kg}$. A risk evaluation was performed in which exposure of the population to these substances is observed and, once found; the MOE was 1036 $\pm 793(<10000)$.

Conclusion: Regarding the risk assessment, it was possible to observe that there is a possibility exposure of the population to these substances since the average of MOE found was $1036 \pm 793$, or $<10000$, characterizing this possible risk.

Keywords: Mycotoxin, Bertholletia excelsa, margin of exposure.

(c) 2020 The Authors. Published by Innovare Academic Sciences Pvt Ltd. This is an open access article under the CC BY license (http://creativecommons. org/licenses/by/4. 0/) DOI: http://dx.doi.org/10.22159/ajpcr.2020.v13i8.37622

\section{INTRODUCTION}

The Brazil nut (Bertholletia excelsa, H.B.K) is one of the most important non-timber species in the Amazon region. It is collected in the forest, industrially improved, and consumed in a dehydrated form or as an ingredient in culinary preparations or products. Despite its exotic flavor and being rich in nutrients, it is associated with aflatoxin (AFL) contamination, a fungal metabolite that is carcinogenic and hepatotoxic to human health [1]. Studies related to AFL occurrence have reported that both the shell and nut are susceptible to contamination and that mycotoxigenic strains may be in the defective fractions of the damaged nuts and peels [2]. Due to environmental conditions in Northern Brazil (temperatures between 30 and $35^{\circ} \mathrm{C}$ and relative air humidity from $80 \%$ to $95 \%$ ), toxin strains, such as Aspergillus flavus, can produce AFLs [3]. Brazil nuts are collected in the forest and transported for drying, which has several stages. However, Brazil nuts can be contaminated at any stage of processing, making them a public health problem since the ingestion of these metabolites may cause adverse health effects [4]. The export of Brazil nuts occurs in the Amazon region and for all countries, and the increasingly dynamic changes in food habits and production worldwide have increased the importance of analyzing the risks associated with their consumption by calculating the exposure, not only by the presence of AFL. Several studies have evaluated the risk of raw materials for food and feed products $[5,6]$. Such risks can be managed to mitigate negative effects to the consumer and, together with scientific support, help properly communicated for health prevention. In Brazil, in addition to the whole exported almond, the nut can be used in the chopped and sliced format to be used in cooking preparations or consumed as snacks. In this context, it is important to evaluate the risks inherent in the presence of AFL in Brazil nut derivatives to contribute to public policies and promote consumer health since it is susceptible to environmental factors that affect contamination. Da Costa et al. observed the effects of adequate drying on reducing the presence of fungi, demonstrating that it is fundamental that humidity is at safe levels and avoid AFL production [7]. In Northern Brazil, despite Brazil nuts and its derivatives being consumed in the daily diet of the population, studies relating AFL levels and Brazil nuts are scarce, as research generally focuses on nuts obtained in forests or already dehydrated and destined for export $[8,9]$. In view of this, the objective of this study was to evaluate exposure to AFL in processed Brazil nut (chopped and sliced) products marketed in Amazonas State. Thus, it will be possible to understand/estimate the impact of the presence of these substances on the consumer diet, contribute to monitoring contamination, provide data to help prevent diseases, and evaluate the relationship of moisture content (MC) and water activity of this sample with AFL concentration.

\section{METHODS}

\section{Sampling}

Brazil nut samples are presented in Figs. 1 and 2. The samples were purchased during the 2017 harvest at the local retail in the city of Manaus/AM/Brazil, thus simulating the acquisition of products derived from nuts. The samples were purchased in the form of sliced (n=15, Fig. 1) and chopped (n=15, Fig. 2). Although they were acquired in different places, most samples came from the same industry. All samples had a shelf life of 6 months.

\section{MC and water activity}

MC was determined by AOAC and water activity (aw) was verified by AquaLab series $4 \mathrm{TE}$ by DECAGON at room temperature $\left(25^{\circ} \mathrm{C}\right)[10]$.

\section{Aflatoxin quantification}

Aflatoxins (AFB1, AFB2, AFG1, and AFG2) were quantified by liquid chromatography using the AOAC Official Method 994.08 [10]. In a $50 \mathrm{~g}$ sample, the AFLs were extracted with $100 \mathrm{~mL}$ of acetonitrile:water 
solution $(90: 10 \mathrm{v} / \mathrm{v})$ and shaken at high speeds for 5 min with subsequent filtering using filter paper. Then, $3 \mathrm{~mL}$ of the filtrate was transferred to a $10 \mathrm{~mL}$ culture tube with the application through MYCOSEP 226 (Romer Labs) cleaning column for extract purification. For derivatization, $0.2 \mathrm{~mL}$ of purified extract and $0.7 \mathrm{~mL}$ of water:glacial acetic acid:trifluoroacetic acid $(35: 10: 5 \mathrm{v} / \mathrm{v})$ were subjected to $65{ }^{\circ} \mathrm{C}$ heating for $8.5 \mathrm{~min}$ to derivatize the AFB1 and AFG1. The resulting solutions were applied and quantified in a high-efficiency liquid chromatography system with mobile phase - acetonitrile, methanol, and ultra-pure water (1:1:4), waters X-Terra column, 150 $\mathrm{mm} \times 4.6 \mathrm{~mm}$, flow of $1.0 \mathrm{~mL} \cdot \mathrm{min}^{-1}$ eluting in isocratic mode, with fluorescence detector: $\lambda$ excitation $-360 \mathrm{~nm}$, and $\lambda$ emission -440 $\mathrm{nm}$; volume of injection of $50 \mu \mathrm{L}$; race time of $20 \mathrm{~min}$. Three pools of AFL standards B1, B2, G1, and G2 (Sigma Aldrich) were used. The limit of detection (LOD) and limit of quantification (LOQ) for each toxin (AFB1/AFB2/AFG1/AFG2) were 0.136/0.136/0.250/0.250 and $0.410 / 0.410 / 0.750 / 0.750 \mu \mathrm{g} / \mathrm{kg}$, respectively. The LOD method was defined by 3 times the signal/noise ratio and LOQ by 6 times the signal/noise. Five points were used to build an analytical curve to obtain the correlation coefficient (R) values for LOD and LOQ. Each point corresponded to a mean of five injections of each extract. The recoveries for each aflatoxin (AFB1, AFB2, AFG1, and AFG2) were 94.5, 73.5, 97.8, and 99.1\%, respectively.

\section{Risk assessment diet}

To estimate exposure to chemicals in food, the calculation proposed by Jardim and Caldas was used using aflatoxin concentration in the food (ng/kg), food consumption ( $\mathrm{kg})$, and body weight $(\mathrm{kg})$

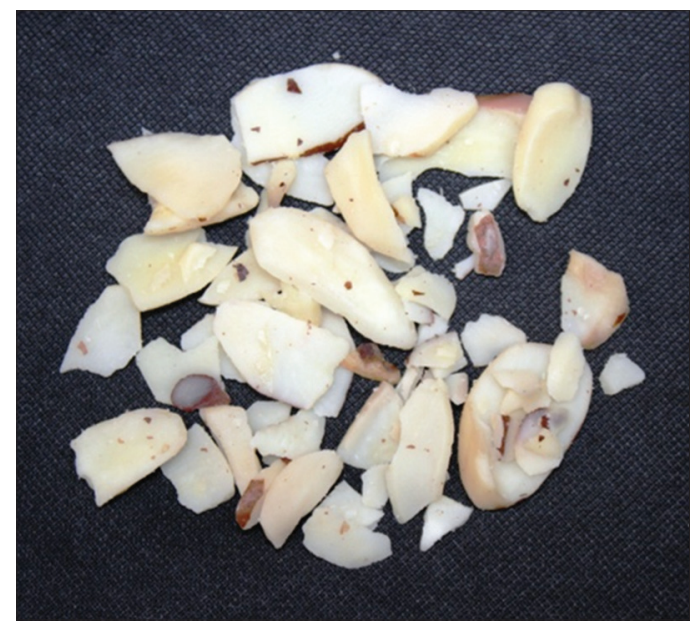

Fig. 1: Sliced Brazil nut

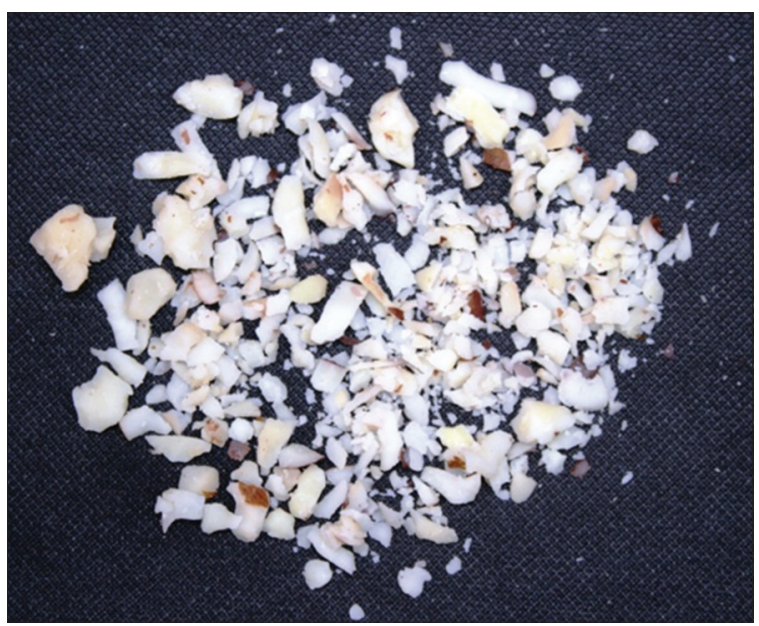

Fig. 2: Chopped Brazil nut (individual or study population) [11]. Equation 1 defines the exposure estimation in $\mathrm{mg} / \mathrm{kg}$ :

$$
\mathrm{EE}=\frac{\text { Compound concentration } \times \text { Food consuption }}{\text { Corporal weight }}
$$

The calculation was performed with samples that presented AFB1 contamination. Fractions of AFB1 below LOQ were not considered. Food consumption used was $10.57 \mathrm{~g} /$ day for high consumption of Brazil nuts [12]. The value of body weight used was $60 \mathrm{~kg}$ [13].

\section{Exposure to carcinogenic and genotoxic substances}

Risk assessors to characterize the risk of exposure to genotoxic use the population margin of exposure (MOE) and carcinogenic substances that can be found in food or feed [14]. Equation 2 was performed for measures of MOE. The MOE can be calculated from the BMDL (benchmark dose lower confidence limit) value, preferably BMDL10, identified as the most appropriate toxicological reference point for estimation:

$$
\mathrm{MOE}=\frac{\mathrm{BMDL}_{10}}{\mathrm{EE}}
$$

According to EFSA, the $\mathrm{BMDL}_{10}$ value of $170 \mathrm{ng} / \mathrm{kg} /$ day is based on carcinogenicity data in rats exposed to AFB1 [14]. The higher the value found for the MOE, the lower the risk of health damage. Values below 10000 may indicate possible problems to human health. The MOE approach provides an indication for the level of safety concern about the presence of a substance in food but does not quantify the risk as such [14].

\section{Statistical analysis}

The relationship between AFLs and aw and MC was analyzed by simple linear regression $[15,16]$. Sample normality was tested using the Shapiro-Wilk test $[17,18]$. For comparisons between two groups and the Wilcoxon test was chosen as an alternative to the Student's t-test when the data presented asymmetry [19-21].

\section{RESULTS AND DISCUSSION}

\section{Aflatoxins versus $\mathrm{MC}$ and aw}

A significant relation of AFL (total) and aw and MC $(\mathrm{p}<0.0004)$ was observed, as well as for AFG1 with these two parameters $(\mathrm{p}<0.0001)$. The same did not occur with AFB1 ( $>0.0633)$. There was no relationship between AFB1 and aw ( $>0.0731)$ and between AFB1 and MC ( $p>0.0633$ ). Data regarding AFL (total), AFG1, and AFB1 did not present normal distribution $(\mathrm{p}<0.0024)$ (Fig. 3). The chopped and sliced nuts were obtained by cutting the almond and differentiated only in the finished product format and by the Wilcoxon test. No effect of the cut shape was observed on aw content ( $\mathrm{p}=0.9591), \mathrm{MC}(\mathrm{p}=0.9999)$, AFB1 ( $p=0.3152)$, AFG1 ( $p=0.8244)$, and AFL (total) $(p=0.9350)$. Both the mean and range of MC levels in this work (Table 1) were below acceptable limits.

With the dehydration processes in which the nut passes through processing, MC decreased from the raw material to the finished product. This was observed in samples of Brazil nuts in pieces by other authors who found an average MC of 2.2 \pm 0.3 [24] and 2.00-3.12\% [25]. For Arrus et al., peeled nuts must be kept with MC around $4.5 \%$ to avoid the growth of A. flavus and AFL production [26]. The environmental

Table 1: Aw and MC levels

\begin{tabular}{llll}
\hline Parameters & Results & \multicolumn{2}{c}{ Maximum acceptable limit $^{\mathbf{a}}$} \\
\cline { 2 - 3 } & Mean \pm SD & Range $^{\mathbf{b}}$ & \\
\hline MC \% & $2.19 \pm 0.004$ & $1.62-2.88$ & $15 \%$ \\
Aw & $0.40 \pm 0.10$ & $0.26-0.54$ & 0.70 \\
\hline
\end{tabular}

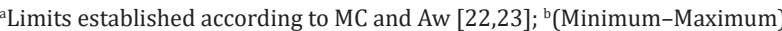
MC: Moisture content, Aw: Water activity 
conditions of the Amazon rainforest, from the period of processing and storage to the consumption of the product, may also influence aw and MC content, which favors AFL production. According to the Codex Alimentarius Commission, aw $<0.7$ is recommended as safe [23]. Regarding AFL (total), the range was $1.24-20.29 \mu \mathrm{g} / \mathrm{kg}$ and two samples $(8 \%)$ were above the legal limit of a max of $10 \mu \mathrm{g} / \mathrm{kg}$ (Table 2). The two analyzed samples that exceeded the limit established by legislation were sliced with AFL (total) $=13.82 \mathrm{ug} / \mathrm{kg}$ and a sample of chopped with $\mathrm{AFL}$ (total) $=20.28 \mu \mathrm{g} / \mathrm{kg}$. It is important to emphasize that, unlike other authors, our samples were from retail and considered "discardable" by the Brazil nut factory. Chopped nuts are quickly consumed in local markets as they have lower prices compared to the whole Brazil nut.
It possibly has lower levels of AFL because they were from production regions of Brazil nuts, generally of the same harvest. On the other hand, Andrade et al. found the average AFL values of $36.9 \mathrm{ug} / \mathrm{kg}$ when analyzing retail samples in Distrito Federal State in Brazil [12]. This is the region that has no Brazil nut factories and buys Brazil nuts from other regions, including Amazon State, and stores them with nuts from past harvests under conditions that may favor mycotoxin production.

Other authors also analyzed cashew nuts and used liquid chromatography as a method of analysis, although they did not specify whether the nut was sliced or chopped. Álvares et al. $(n=3)$ collected cashew nuts in Acre State (Brazil), AFL (mean of AFL [total=0.86 $\mu \mathrm{g} / \mathrm{kg}$ ])

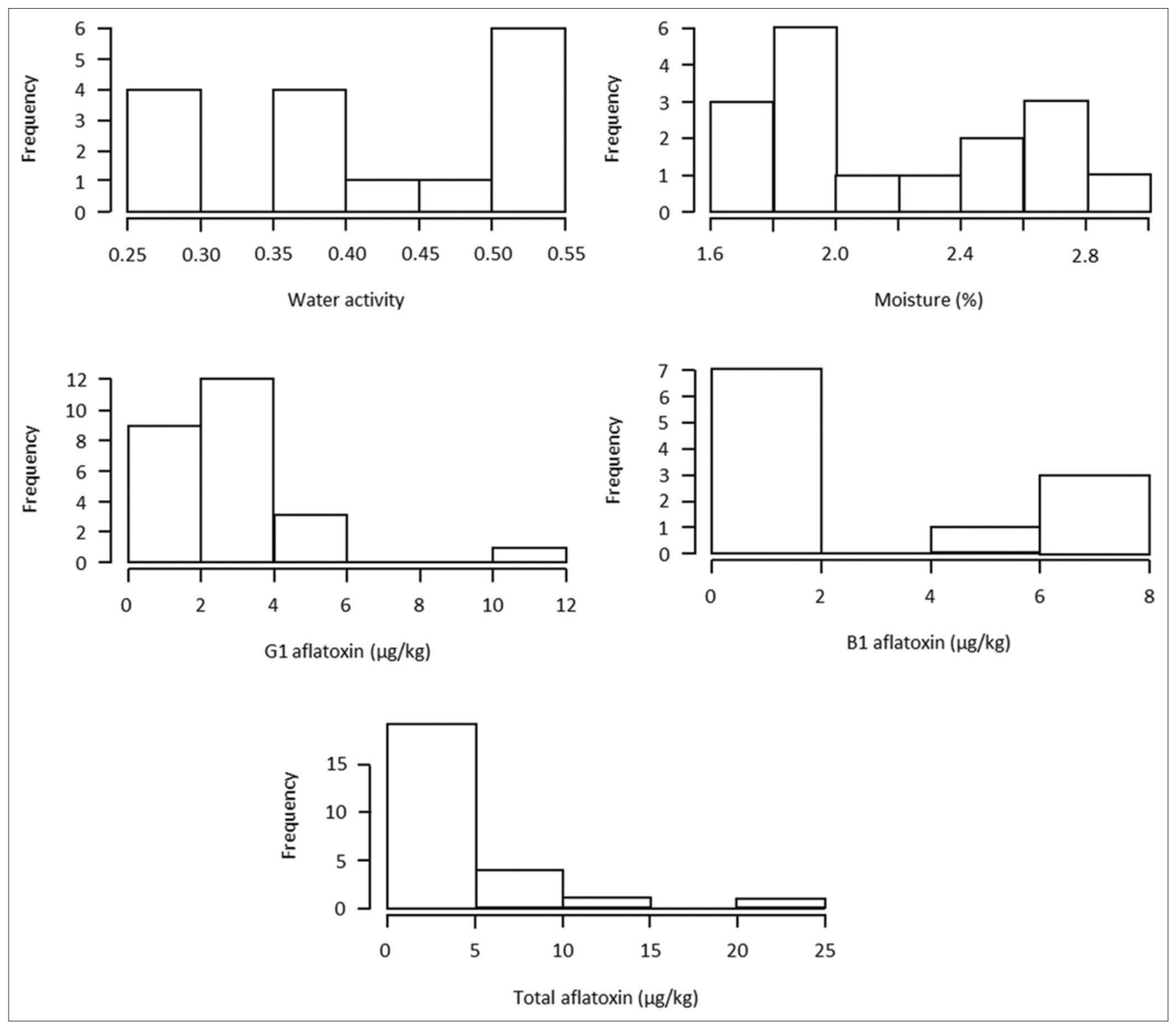

Fig. 3: Aflatoxin versus water activity and moisture content in sliced and chopped Brazil nut samples

Table 2: Aflatoxin levels in Brazil nuts - sliced and chopped

\begin{tabular}{|c|c|c|c|c|c|c|}
\hline \multirow[t]{2}{*}{ Samples } & \multicolumn{5}{|c|}{ Results $\mu \mathrm{g} / \mathrm{kg}(\text { mean } \pm \mathrm{SD})^{\mathrm{a}}$} & \multirow[t]{2}{*}{$\%$ samples $>10^{b}$} \\
\hline & AFB1 & AFB2 & AFG1 & AFG2 & AF total & \\
\hline 30 & $\begin{array}{l}2.7 \pm 2.87 \\
(0.5-7.86)\end{array}$ & $\begin{array}{l}1.19 \pm 0.036 \\
(1.16-1.21)\end{array}$ & $\begin{array}{l}2.85 \pm 2.17 \\
(0.75-11.32)\end{array}$ & $\begin{array}{l}1.34 \pm 0.54 \\
(0.96-1.73)\end{array}$ & $\begin{array}{l}4.25 \pm 4.29 \\
(1.24-20.29)\end{array}$ & $8 \%$ \\
\hline
\end{tabular}

${ }^{a}$ Results are expressed in average \pm standard deviation (range); the limit of quantification were: AFB1=0.410, AFB2=0.410, AFG1=0.750, and AFG2=0.750; ${ }^{b}$ Limit established in legislation up to $10 \mu \mathrm{g} / \mathrm{kg}$ of AFL and up to $2.0 \mu \mathrm{g} / \mathrm{kg}$ of AFB1 [27] 
Table 3: Characterization of the risk

\begin{tabular}{ll}
\hline $\begin{array}{l}\text { Exposure ng/kg/day } \\
\text { (mean } \pm \text { SD) }^{\mathbf{a}}\end{array}$ & $\begin{array}{l}\text { MOE }^{\mathrm{b}} \\
\text { (mean } \pm \text { SD) }^{\mathbf{c}}\end{array}$ \\
\hline $0.48 \pm 0.51$ & $1036 \pm 793$ \\
$(0.09-1.38)$ & $(123-1977)$ \\
\hline
\end{tabular}

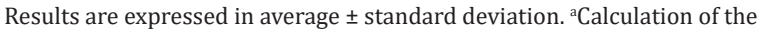
exposure based on high consumption of $10.55 \mathrm{~g}$ of Brazil nuts per day [12]. ${ }^{b}$ Based on a toxicological reference $\left(\mathrm{BMDL}_{10}\right.$ ) of $170 \mathrm{ng} / \mathrm{kg} /$ day [14]. 'Results are expressed in average \pm standard deviation (range)

was also found, but they met the limits of the legislation [25]. Iamanaka et al. evaluated samples sold at a supermarket $(\mathrm{n}=21)$ and found a mean total AFL of $0.24 \mu \mathrm{g} / \mathrm{kg}$ and maximum of $0.98 \mu \mathrm{g} / \mathrm{kg}$ [28]. In our study, the highest AFB1 content found was 7.86, which exceeded the maximum limit allowed by the legislation of $2 \mu \mathrm{g} / \mathrm{kg}$ for AFB1, the other three samples analyzed also exceeded this limit. Cunha et al. evaluated multiple toxins in Brazil nuts purchased in Portugal and reported that it was possible to associate the data of occurrence and consumption, evaluate the exposure, and characterize the risk to the consumption of nut tree products by the population [29]. Therefore, a promising field for future studies is the study of other mycotoxins in samples from retail in the Amazon region. Another important aspect to consider is that these products did not present adequate packaging, that is, lowdensity plastic, with passage to sunlight and that may accelerate the degradation process of the lipid fraction of the chestnut. Silva et al. already considered this by analyzing processed nuts and observed negative effects of processing in fat and amino acids that decrease product quality [30].

\section{Exposure evaluation}

According to EFSA, the probable risk is characterized when the MOE value found is below 10,000 [14]. The mean value of the exposure and MOE values is shown in Table 3, where the highest value was 1977, that is, $<10,000$, which already indicates a likely risk to human health. All Brazil nut samples that presented AFB1 contamination analyzed in our study presented $\mathrm{MOE}<10,000$, which demonstrates a possible exposure of the population to this toxic compound, even if they are present at a level below the allowed by the legislation (max $2 \mu \mathrm{g} / \mathrm{kg}$ ). These data are important in the area of public health within the monitoring of food to support decision-making with public policies for Brazil nuts by competent bodies.

A study by Andrade et al. evaluated AFL in products consumed in Brazil (peanuts, rice, nuts, and corn), including Brazil nuts without peels, and found a total exposure value of $16.3-27.6 \mathrm{ng} / \mathrm{kg} /$ day, and the values found for Brazil nuts without peels were $4.3-4.7 \mathrm{ng} / \mathrm{kg} /$ day [12]. The values found in our study ranged from 0.09 to $1.38 \mathrm{ng} / \mathrm{kg} /$ day. For the MOE values found in the study by Andrade et al., values between 25.0 and 25.8 were found, which are values $<10000$, characterizing the possible risk $[12,14]$. According to Jardim and Caldas, the MOE is not a quantification of risk, but its value is used to classify substances, indicates the level of concern, and establishes the priorities of action for the risk managers to reduce the risk to the health of the population consuming these products [11].

\section{CONCLUSION}

The samples of chopped and sliced Brazil nuts used in this study had a mean of $2.19 \% \mathrm{MC}$ and aw 0.40 , whose values, because they are below acceptable maximum limits, guarantee the stability of the nut samples for these parameters. All analyzed samples presented AFL, and two samples (8\%) had total AFL above the maximum limit allowed by the $10 \mu \mathrm{g} / \mathrm{kg}$ legislation. As regards for the specific contamination by AFB1, which is the most toxic and carcinogenic, $16 \%$ of the analyzed samples presented AFB1 concentration above the limit of $2 \mu \mathrm{g} / \mathrm{kg}$ of AFB1. Regarding the risk assessment, it was possible to observe that there is a possibility exposure of the population to these substances since the average of MOE found was $1036 \pm 793$, or $<10000$, characterizing this possible risk. In view of the results obtained, greater monitoring of the presence of AFLs during the processing/commercialization of these samples is necessary to prevent contamination and reduce the risk.

\section{ACKNOWLEDGMENTS}

The authors are thankful to FAPEAM for support the project.

\section{AUTHORS' CONTRIBUTIONS}

Dr. Ariane M. Kluczkovski analyzed the data and wrote the manuscript, whereas Arine Lopes, Samir Pinto, and Diana Coelho carried out the laboratory work. Dr. Augusto Kluczkovski-Junior was responsible for produce the jam samples. Both the authors read and approved the final manuscript.

\section{CONFLICTS OF INTEREST}

The authors declare that they have no conflicts of interest in publishing this research article.

\section{AUTHORS' FUNDING}

The authors themselves bear the publication fees of this paper.

\section{REFERENCES}

1. International Agency for Research on Cancer. Monographs on the evaluation of carcinogenic risks to humans. In: Some Naturally Occurring Substances: Food Items and Constituents, Heterocyclic Aromatic Amines and Mycotoxins. Vol. 56. Lyon, France: International Agency for Research on Cancer; 1993. p. 1-599.

2. Vargas EA, Santos EA, Whitaker TB, Slate AB. Determination of aflatoxin risk components for in-shell Brasil nuts. Food Addit Contam Part A 2011;28:1242-60

3. Luo J, Taniwaki MH, Iamanaka BT, Vogel RF, Niessen L. Application of loop-mediated isothermal amplification assays for direct identification of pure cultures of Aspergillus flavus, A. nomius, and A. caelatus and for their rapid detection in shelled Brazil nuts. Int $J$ Food Microbiol 2014;172:5-12.

4. Bando E, Goncales LN, Tamura NK, Machinski M Jr. Biomarkers for assessment of human exposure to mycotoxins. J Bras Patol Med Lab 2007; $43: 175-80$.

5. Nugraha A, Ivonne K, Rietjens MC. Risk assessment of aflatoxin B1 exposure from maize and peanut consumption in Indonesia using the margin of exposure and liver cancer risk estimation approaches. Food Chem Toxicol 2018;113:134-44.

6. Van der Fels-Klerx JH, Adams P, de Jong J, Hoogenboom R, de Nijs M, Bikker P. A model for risk-based monitoring of contaminants in feed ingredients. Food Control 2017;72:211-8.

7. Da Costa DA, Alvares VS, Kusdra JF, Nogueira RM, Maciel VT, Miqueloni DP. Quality of in-shell Brazil nuts after drying using a pilot natural convection oven in the state of Acre, Brazil. Braz J Food Technol 2017;20:2015104.

8. Baquião AC, Zorzete P, Reis TA, Assunção E, Vergueiro S, Correa B. Mycoflora and mycotoxins in field samples of Brazil nuts. Food Control 2012;28:224-9.

9. Pacheco AM, Scussel VM. Aflatoxins evaluation on in-shell and shelled dry Brazil nuts for export analysed by LC-MS/MS-2006 and 2007 harvests. W Mycotoxin J 2010;2:295-304.

10. Association of Official Analytical Chemists. AOAC Official Methods of Analysis. $20^{\text {th }}$ ed. Gaithersburg, MD, USA: Association of Official Analytical Chemists International; 2016.

11. Jardim AN, Caldas E. Chemical dietary exposure and the risks to human health. Quim Nova 2016;32:1898-909.

12. Andrade PD, de Mello MH, França JA, Caldas ED. Aflatoxins in food products consumed in Brazil: A preliminary dietary risk assessment. Food Addit Contam Part A Chem Anal Control Expo Risk Assess 2013;30:127-36.

13. Instituto Brasileiro de Geográfia e Estatística. Pesquisa de Orçamentos Familiares 2008-2009. Raw Data. Rio de Janeiro, Brazil: Instituto Brasileiro de Geográfia e Estatística; 2011.

14. European Food Safety Authority. Opinion of the scientific committee on a request from EFSA related to a harmonized approach for risk assessment of substances which are both genotoxic and carcinogenic. EFSA 2005;282:1-31. 
15. Zar JH. Biostatistical Analysis. $5^{\text {th }}$ ed. Upper Saddle River: PrenticeHall/Pearson; 2010. p. 944

16. Hoffmann R. Análise de Regressão: Uma Introdução à Econometria. $5^{\text {th }}$ ed. Piracicaba: Rodolfo Hoffmann; 2016. p. 393.

17. Noughabi HA, Arghami NR. Monte Carlo comparison of seven normality tests. J Stat Comput Simul 2011;81:965-72

18. Yap B, Sim C. Comparisons of various types of normality tests. J Stat Comput Simul 2011;81:2141-55.

19. Blair CR, Higgins JJ. A comparison of the power of Wilcoxon's ranksum statistic to that of student's t statistic under various non-normal distributions. J Educ Stat 1980;5:309-35.

20. Sawilowsky SS. Abelson's paradox and the Michelson-Morley experiment. J Modern Appl Stat Meth 2005;4:352.

21. Fay MP, Proschan MA. Wilcoxon-Mann-Whitney or T-test? On assumptions for hypothesis tests and multiple interpretations of decision rules. Stat Surv 2010;4:1-39.

22. Ministry of Agriculture, Livestock and Supply. Criteria and procedures for the control hygiene and health the Brazil nut and its by products. In: Diário Oficial da República Federativa do Brasil. Brasília, DF: Ministry of Agriculture, Livestock and Supply; 2010.

23. World Health Organization. Proposed draft maximum level for total aflatoxins in Brazil nuts. In: Joint FAO/WHO Food Standards Programme Codex Alimentarius Commission. Rome: World Health
Organization; 2010

24. Pacheco AM, Martins M. Brazil nut sorting for aflatoxin prevention: A comparison between automatic and manual shelling methods. Food Sci Tech 2013;33:369-75.

25. Álvares VS, Castro IM, Costa DA, Lima AC, Madruga AL. Quality of Brazil nuts marketed in Rio Branco, Acre. Acta Amazonica 2012;42:269-74

26. Arrus K, Blank G, Abramson D, Clearc R, Holleya RA. Aflatoxin production by Aspergillus flavus in Brazil nuts. J Stored Prod Res 2005;41:513-27.

27. Agência Nacional de Vigilância Sanitária. Provides for Maximum Tolerated Limits (LMT) for Mycotoxins in Food. Brazil: Agência Nacional de Vigilância Sanitária; 2011.

28. Iamanaka BT, Nakano F, Lemes DP, Taniwaki M. Aflatoxin evaluation in ready-to-eat Brazil nuts using reversed-phase liquid chromatography and post-column derivatization. Food Addit Contam Part A 2014;31:917-23

29. Cunha SC, Sa VM, Fernandes JO. Multiple mycotoxin analysis in nut products: Occurrence and risk characterization. Food Chem Tech 2018;114:260-9.

30. Silva RF, Ascheri JL, Souza JM. Influence of Brazil nut processing on the quality of nuts. Sci Agro Technol 2010;34:445-50. 